\title{
Efficiency of Macedonian Insurance Companies: A DEA Approach
}

\author{
Vesna Micajkova \\ Integrated Business Faculty, Skopje, Macedonia
}

Email address:

vmicajkova@yahoo.com

\section{To cite this article:}

Vesna Micajkova. Efficiency of Macedonian Insurance Companies: A DEA Approach. Journal of Investment and Management. Vol. 4, No. 2, 2015, pp. 61-67. doi: 10.11648/j.jim.20150402.11

\begin{abstract}
The purpose of this paper is to estimate the efficiency of the insurance sector of Republic of Macedonia for the period 2009-2013. Technical, pure technical and scale efficiency of 11 Macedonian insurance companies have been measured using Data Envelopment Analysis (DEA), both CCR and BCC output-oriented model. The results from the analysis indicate an increase of the average efficiency during the almost whole observed period. The scale efficiency follows the same trend. When estimating the BCC model, the number of efficient insurance companies and the average efficiency for the sector is higher than in the CCR case, implying that the main source of inefficiency is due to scale inefficiencies. The average technical efficiency score of Republic of Macedonia in 2013 of 0.84387 indicates relatively high efficiency of the insurance sector. The efficiency problem of each insurance company has been specified particularly.
\end{abstract}

Keywords: Data Envelopment Analysis, Macedonia, Insurance Sector Efficiency, Scale Efficiency, Technical Efficiency, Pure Technical Efficiency

\section{Introduction}

Insurance companies are financial institutions that play an important role in the economy of a country through saving mobilization, risk transfer and financial intermediation. In addition, insurance companies provide economic and social benefits in the society by prevention of losses, reduction in anxiousness, fear and increasing employment. Resent research shows that the efficiency of financial intermediation and transfer of risk can affect economic growth while at the same time institutional insolvencies can result in system crises which have unfavorable consequences for the economy as a whole (Ayele, 2012). Therefore, the efficiency of the insurance companies is an important subject of scientific interest. Measurement of insurance companies' efficiency increases the quality of their activities and also assists them to identify and solve their problems (Shahroudi at all, 2012).

The purpose of this paper is to estimate the efficiency of the insurance sector of the Republic of Macedonia using Data Envelopment Analysis (DEA). Using both CCR and BCC output-oriented models, the relative efficiency of the Macedonian insurancesector has been measured for the period 2009-2013 (separately for each year and each insurance company). According to our knowledge this is the first efficiency study of the insurance sector of Republic of Macedonia.

\section{Data Envelopment Analysis (DEA)}

Data envelopment analysis (DEA) is a nonparametric method, most popular in operations research and economics for the estimation of production frontier. It is used to empirically measure productive efficiency of Decision Making Units (or DMUs). The efficiency of a DMU is measured relative to all other DMUs with the simple restriction that all DMUs lay on or below the extreme frontier. Unlike statistical procedures that are based on central tendencies, DEA is a process of extremes directed at the frontier rather than at central tendencies. DEA analysis each DMU separately and calculates a maximum performance measure for each unit.

DEA was introduced in 1978 by Charnels, Cooper and Rhodes. Their model, known as the CCR model, was named after its founders. The CCR model is a basic DEA model that presupposes that there is no significant relationship between the scale of operation and efficiency by assuming constant return to scale (CRS) and it delivers the overall technical efficiency. The CRS assumption is only justifiable when all 
DMUs are operating at an optimal scale. Because in practice DMUs face economies or diseconomies to scale, in 1984 the CCR model was extended by relaxing the CRS assumption. The BCC model was introduced in order of assessing the efficiency of DMUs characterized by variable return to scale (VRS). (Stavarek\&Repkova, 2012)

Vincova (2005) defines DEA models as models that evaluate $\mathrm{n}$ productive units, DMUs, where each DMU takes $\mathrm{m}$ different inputs to produce s different outputs. The essence of DEA models in measuring the efficiency of productive unit DMUq lies in maximising its efficiency rate. However, subject to the condition that the efficiency rate of any other units in the population must not be greater than 1 . The models must include all characteristics considered, i.e. the weights of all inputs and outputs must be greater than zero. The CCR model can be defined as a linear divisive programming model: maximize

$$
\frac{\sum \mathrm{i}_{i} y_{\mathrm{iq}}}{\sum j^{v_{\mathrm{j}} x_{\mathrm{jq}}}}
$$

subject to

$$
\begin{gathered}
\frac{\sum \mathrm{i}^{u_{\mathrm{i}} y_{\mathrm{ik}}}}{\sum \mathrm{j}^{v_{\mathrm{j}} \mathrm{j}_{\mathrm{jk}}}} \leq 1 \mathrm{k}=1,2, \ldots, \mathrm{n}, \\
\mathrm{ui} \geq \in \mathrm{i}=1,2, \ldots, \mathrm{s} \text { vj } \leq \in \mathrm{j}=1,2, \ldots, \mathrm{m}
\end{gathered}
$$

This model can be transformed into a matrix: Maximize

$$
\mathrm{z}=\mathrm{u}^{\mathrm{T}} \mathrm{Yq}
$$

subject to $v^{\mathrm{T}} \mathrm{Xq}=1$

$$
\begin{gathered}
\mathrm{u}^{\mathrm{T}} \mathrm{Y}-\mathrm{v}^{\mathrm{T}} \mathrm{X} \leq 0 \\
\mathrm{u} \geq \in \\
\mathrm{v} \leq \in
\end{gathered}
$$

The dual model to this can be stated as follows: Minimize

$$
f=\theta-\in\left(\mathrm{e}^{\mathrm{T}} \mathrm{s}^{+}+\mathrm{e}^{\mathrm{T}} \mathrm{s}^{-}\right)
$$

subject to $\mathrm{Y} \lambda-\mathrm{s}^{+}=\mathrm{Y}_{\mathrm{q}}$

$$
\begin{gathered}
\mathrm{X} \lambda+\mathrm{s}^{+}=\theta \mathrm{X}_{\mathrm{q}} \\
\lambda, \mathrm{s}^{+}, \mathrm{s}^{-} \geq 0
\end{gathered}
$$

where $\lambda=\left(\lambda_{1}, \lambda_{2}, \ldots, \lambda_{n}\right), \lambda \geq 0$ is a vector assigned to individual productive units, $\mathrm{s}+$ and $\mathrm{s}$ are vectors of addition input and output variables, $\mathrm{e}^{\mathrm{T}}=(1,1, \ldots, 1)$ and $\in$ is a constant greater than zero, which is normally pitched at $10^{-6}$ or $10^{-8}$. In evaluating the efficiency of unit $\mathrm{DMU}_{\mathrm{q}}$, model (3) seeks a virtual unit characterised by inputs $\mathrm{X} \lambda$ and outputs $\mathrm{Y} \lambda$, which are a linear combination of inputs and outputs of other units of the population and which are better that the inputs and outputs of unit $\mathrm{DMU}_{\mathrm{q}}$ which is being evaluated. Unit $\mathrm{DMU}_{\mathrm{q}}$ is considered to be CCR efficient if the optimum value of the model (3) objective function equals one. In the inefficient units the objective function of the model is lower than one.

Models (2) and (3) are input-oriented - they try to find out how to improve the input characteristics of the unit in order of efficiency increase. There are output-oriented models as well. Such a model could be written as follows:

Maximize

$$
\mathrm{g}=\Phi+\in\left(\mathrm{e}^{\mathrm{T}} \mathrm{s}^{+}+\mathrm{e}^{\mathrm{T}} \mathrm{s}^{-}\right)
$$

subject to $\mathrm{Y} \lambda-\mathrm{s}^{+}=\Phi \mathrm{Y}_{\mathrm{q}}$

$$
\begin{aligned}
& X \lambda+s^{-}=X_{q} \\
& \lambda, s^{+}, s^{-} \geq 0
\end{aligned}
$$

In the output-oriented models as well as in the input-oriented, a DMU is considered to be efficient if the objective function of the model is one.

Models (2), (3) and (4) are CCR models i.e. they assume constant returns to scale. These models can be converted to a BCC models with a variable return to scale by inclusion of a condition of convexity $\mathrm{e}^{\mathrm{T}} \lambda=1$. The results of the CCR model are considered as technical efficiency scores, the results of a $\mathrm{BCC}$ model are considered as pure technical efficiency scores, and the ratio of the $\mathrm{CCR}$ scores to $\mathrm{BCC}$ scores gives the scale efficiency score.

Kumar and Gulati (2008) give a very concise elaboration of the concept of technical, pure technical and scale efficiency which we consider to be very important in understanding the DEA method and reading its results. Technical efficiency (TE) relates to productivity of inputs. A technical efficiency of a firm is comparative measure of how well it is actually processes inputs to achieve its outputs, as compared to its maximum potential for doing so, as represented by its production possibility frontier. The TE is measured under the assumption of constant return to scale. The pure technical efficiency (PTE) measure is obtained by estimating the efficient frontier under the assumption of a variable return to scale. It reflects the managerial performance to organize the inputs in the production process. On the other site, the measure of scale efficiency provides the management to choose the scale of production that will attain the expected production level. Inappropriate size of an insurance company (too large or too small) may sometimes be a cause of technical inefficiency. This is referred as scale inefficiency and takes two forms: decreasing returns to scale (DRS) and increasing returns to scale (IRS). DRS (also known as diseconomies of scale)imply that aninsurance company is too large to take full advantage of scale and has supra-optimum scale size. In contrast, an insurance experiencing IRS (also known as economies of scale) is too small for its scale of operations and, thus, operates at sub-optimum scale size. An insurance company is scale efficient if it operates at constant returns to scale (CRS).

\section{Model and Input and Output Selection}

An important decision when employing frontier efficiency models involves the choice of inputs and outputs, since the definition of these factors can significantly impact the results 
of a study (Eling and Luhnen). The selection of appropriate variables representing inputs and outputs is particularly difficult for insurance companies compared to manufacturing firm where attributing inputs and outputs is less challenging (Diboky and Ubl, 2007). In follows we will present some theoretical discussion on this subject.

\subsection{Output Specification}

In existing studies of insurance companies' efficiency we find three principal approaches to define outputs: the asset (intermediation) approach, the user-cost approach and value-added approach.

The assets (intermediation) approach treats financial service firms as pure financial intermediaries which borrow funds from their customers which are invested and than transformed into assets. Interest payments are paid out to cover the time value of the funds used (Sinha and Chatterjee). The main objective of this approach is to maximize simultaneously the value of claims' ownership and capital return adjusted to risk (Jarraya and Bouri, 2012). Taking into consideration only the intermediation service of the insurance company is considered as the main disadvantage of this approach. Insurance companies offer other services in addition to financial intermediation. Ignoring these other services, such as risk-pooling and risk-bearing services, allocated to the insurance company leads to erroneous results in efficiency studies.

The user-cost approach was developed by Hancock (1985). It determines whether a financial product is an input or an output by analyzing if its net contribution to the revenues of an insurance firm is positive or negative. According to that, a product is considered an output, if its financial return exceeds the opportunity costs of funds or if the financial costs of a liability are lower than the opportunity costs. Otherwise, the financial product would be classified as an input (Sinha and Chatterjee).Jarraya and Bouri (2012) consider this approach, at the theoretical level, as the most ideal, but at a practical level it is almost impossible to find the necessary data.Eling and Luhnen confirm that there is no practical applicability of this approach, since they haven't found any study on efficiency measurement in the insurance industry, out of 83 analyzed, that employs the user-cost approach.

The value-added approach differs from the asset approach and the user-cost approach as it considers all asset and liability categories to have some output characteristics. Those categories which have substantial value added are than used as the important outputs. The remaining categories are treated as rather unimportant outputs, intermediate products, or inputs. Sinha and Chatterjee emphasize that an important advantage of this approach compared to the user-cost approach consists in the fact thatthe value added approach uses operating cost data rather than determining the costs implicitly or using opportunity costs. Many authors (Jarraya and Bouri (2012), Sinha and Chatterjee, Eling and Huang (2011), Eling and Luhnen) consider the value-added approach as the most appropriate method for measuring output of financial firms. This approach is widely used in insurance companies' efficiency studies.

In the value-added approach, insurer's outputs consist primarily of intangible financial services, therefore, it is necessary to define suitable proxies that are highly correlated with the quantity of financial services provided (Laverty and Grace, 2008). The most common proxies used in the literature for value-added are either premiums or the present value of real losses incurred. Eling and Huang (2011) emphasizes that out of 69 studies using value-added approach for efficiency measurement in the insurance industry, 35 studies use insurance premium as output and 32 specify claims/present value of claims (property-liability) or benefit/net incurred benefits (life) as output in the efficiency analysis. Two of 69 studies use neither of the two main proxies.

We have decided to adopt the value-added approach when investigating the efficiency of the insurance sector of Republic of Macedonia. Regarding the data availability we will consider gross written premium and gross claims settledas outputs in our efficiency study.

\subsection{Input Specification}

There are three main insurance inputs: labor, business service and materials, and capital. Labor can be further divided into agent and home-office labor. The category of business service and materials is usually not further subdivided, but includes items like travel, communications, and advertising. At least three categories of capital can be distinguished: physical, debt and equity.

Qui and Chen (2006) consider labor as the most important input in the financial service industry. In insurance companies, no raw materials are required, and cost of labor is the major component of costs. Since data on numbers of employees or hours worked in many countries are not publicly available some authors define the quantity of labor as administration or management cost divided by a publicly available wage variables or price index (see Diboky and Ubl (2007), and Eling and Huang, (2011)).Most studies use the operating expenses as a proxy for labor, since the authors consider that the majority of operating expenses in the insurance industry are due to commissions and employees salaries (see Jarraya and Bouri (2012), Sihna and Chatterjee,Shahroudi at all (2012)).Physical capital is often included in the business service and material category (Diboky and Ubl, 2007), but many authors consider equity capital as an imperative input (Borges at all, 2008, Qui and Chen, 2006). There are authors that think that equity and debt capitalhave the same importanceand use both of them in the insurance companies' efficiency studies (see Eling and Huang, (2011), Barros and Obijiaku, (2007)), andsome studies do not include any category of capital as an input(Shahroudi and all, 2012, Sihna and Chatterjee).

Eling and Luhnen have reviewed 83 studies on frontier efficiency measurement in the insurance industry and made the following conclusions regarding the choice of input factors: 55 out of 83 studies use at least labor and capital as inputs and most of them also add a third category (miscellaneous, mostly business services). Out of those 55 studies, 15 differentiate between agent and non agent labor. Also, the number of 
studies differentiating between equity and debt capital is quite low; only ten papers do so. There are a further nine studies that do not cover capital explicitly, i.e., they consider labor only or labor and an additional composite category.

Regarding the data availability as inputs in the study investigating the efficiency of Macedonian insurance sector we will consider the following: administrative expenses, commission expenses and total capital. The administrative expenses will be consider as a proxy for a home-office labor, assuming that staff costs have the largest part in the administrative expenses of the Macedonian insurance companies. The commission expenses represent theagents' costs and the total capital consists of equity and debt capital.

\subsection{Model Specification}

When choosing the inputs and outputs of the model few suggestions from Sarkis (2002) have been taken into consideration. First suggestion is about the number of inputs and output compared to number of DMUs. Second suggestion is to reduce the correlated data sets for input/output factors. And the third suggestion is to fix the imbalance in data magnitudes by mean normalize of the data.

Sarkis (2002) emphasizes that the choice and the number of inputs and outputs, and the DMUs determine how good of a discrimination exists between efficient and inefficient units. He gives a review of different authors' opinion about the number of inputs and outputs compared to a number of DMUs in a DEA model. According to Boussofiane at al. (1991) the minimal number of DMUs should be the multiple of the number of inputs and number of outputs. Golany and Roll (1989) establish a rule of thumb that the number of units should be at least twice the number of inputs and outputs considered, while Bowlin (1998) thinks that the number of DMUs should be at least three times of the number of the inputs and the outputs. Dyson at al (2001) recommend a total of two times the product of the number of input and output variables. For example in a 3 input and 4 output model Boussofiane at all recommend using 12DMUs, Golany and Roll recommend using 14 DMUs, while Bowlin recommends 21 DMUs, and Dyson et al. recommend 24. The number of DMUs in the model applied in this study is predefined by the number of insurance companies operating on the financial marketof Republic of Macedonia in the observed period from 2009 to 2013. The number of DMUs is 11 . According to the literature recommendation the maximum total of the number of inputs and outputs should vary between 3 and 6 .

The first step in choosing the inputs and the outputs that will be applied in this study is examining the correlation between the inputs and outputs that we consider using. The results of the correlation analysis are presented in the following tables.

Table 1. Selected inputs correlation analysis.

\begin{tabular}{llll}
\hline & $\begin{array}{l}\text { Administrative } \\
\text { Expenses }\end{array}$ & $\begin{array}{l}\text { Commission } \\
\text { Expenses }\end{array}$ & Total Capital \\
\hline $\begin{array}{l}\text { Administrative } \\
\begin{array}{l}\text { Expenses } \\
\text { Commission }\end{array}\end{array}$ & 1 & \\
\hline
\end{tabular}

\begin{tabular}{llll}
\hline & $\begin{array}{l}\text { Administrative } \\
\text { Expenses }\end{array}$ & $\begin{array}{l}\text { Commission } \\
\text { Expenses }\end{array}$ & Total Capital \\
\hline $\begin{array}{l}\text { Expenses } \\
\text { Total Capital }\end{array}$ & 0.555206291 & 0.259196177 & 1 \\
\hline
\end{tabular}

Source: Author

Table 1 presentsrelatively weak correlation between the analyzed inputs.Sarkis (2002) recommends that eliminating the highly correlated inputs will have an insignificant effect on the efficiency scores. But in this case we can not eliminate any of the inputs due to high correlation, so our model will include all three above mentioned inputs.

Regarding the output selection, the results from the output correlation analysis (presented in table 2) suggest very strong correlation between the gross written premium and gross claims settled.Using two highly correlated outputs will have insignificant effect on the efficiency score, so we have decided to eliminate the gross claims settled, and to use gross written premium as a single output in our efficiency model.

Table 2. Selected outputs correlation analysis.

\begin{tabular}{lll}
\hline & Gross Written Premium & Gross Claims Settled \\
\hline $\begin{array}{l}\text { Gross Written } \\
\text { Premium }\end{array}$ & 1 & \\
$\begin{array}{l}\text { Gross Claims } \\
\text { Settled }\end{array}$ & 0.956966273 & 1 \\
\hline
\end{tabular}

Source: Author ${ }^{2}$

The model that we have chosen has three inputs, two outputs and 11 DMUs and as such is suitable for efficiency measurement according to every above mentioned literature recommendation, except of Bowlin's ${ }^{3}$. After the inputs and the outputs are selected Sarkis (2002) recommends mean normalizing of the data in order of reducing their imbalance. The first step of that process is to find the mean of the data set for each input and output. The second step is to divide each input or output by the mean for that specific factor. Before efficiency scores calculation we have followed Sarkis recommendation and mean normalized the data on inputs and outputs applied in our model.

Regarding the input-output orientation of the model, according to Borges at all (2008) the choice should be based on the market conditions of the DMU's. As a general rule of thumb, in competitive markets, DMU's are output-oriented, since we assume that inputs are under control of the DMU, which aims to maximize its output subject to market demand. Therefore we choose output orientation for our DEA model.

\section{Efficiency and Empirical Results}

Using both CCR and BCC output-oriented models, the relative efficiency of the Macedonian insurance sector has

\footnotetext{
1 The analysis is made upon data for every particular insurance company included in the analysis for period from 2009 to 2013 .

2 The analysis is made upon data for every particular insurance company included in the analysis for period from 2009 to 2013.

3 According to Bowlin our model should have 12 DMUs.
} 
been measured for the period 2009-2013 (separately for each year and each insurance company). As a statistical basis for input and output data, ISA (The Insurance Supervision Agency) insurance industry reports have been used.Table 3 presents descriptive statistics for inputs and outputs applied.

The results from the CCR model (table 4) indicate a growth in the efficiency score of the Macedonian insurance sector in almost whole observed period from 2009 to 2013. A decrease of the efficiency has been detected only in 2010.The average efficiency in 2013 was 0.84387 that implies that there is room for the mean insurance company's efficiency to be upgraded by $15.6 \%$. The most efficient insurance companies are Eurolink, Sava and Triglav with average efficiency score higher than 0.9. The most inefficient insurance company is Insigwith average score of 0.46966 . The number of efficient units per year varies from two to four. ${ }^{4}$

When estimating the BCC model (Table 5), the number of efficient insurance companies and the average efficiency for the sector is higher than in the CCR case, implying that the main source of inefficiency is due to scale inefficiencies. The number of efficient units per year varies from 5 to $8 .{ }^{5}$ Five insurance companies (Viner, Eurolink, Kroacija, Sava and Triglav) are efficient unitsduring the whole observed period. In general the picture remains the same i.e. the average efficiency of the Macedonian insurance sector rises during the whole observed period.

Table 3. Descriptive statistics for inputs and outputs.

\begin{tabular}{|c|c|c|c|c|c|c|}
\hline & & 2009 & 2010 & 2011 & 2012 & 2013 \\
\hline \multicolumn{7}{|l|}{ Inputs } \\
\hline \multirow[t]{3}{*}{ Administrative Expenses } & Mean & 145,914 & 131,616 & 120,681 & 111,857 & 114,503 \\
\hline & Med & 139,318 & 114,977 & 98,841 & 108,773 & 120,177 \\
\hline & StDev & 85,721 & 62,550 & 69,646 & 50,908 & 43,536 \\
\hline \multirow[t]{3}{*}{ Commission Expenses } & Mean & 38,145 & 31,960 & 36,330 & 37,036 & 39,533 \\
\hline & Med & 30,629 & 30,249 & 34,580 & 37,198 & 29,223 \\
\hline & StDev & 27,460 & 15,299 & 20,153 & 16,542 & 19,446 \\
\hline \multirow[t]{3}{*}{ Total Capital } & Mean & 380,401 & 331,647 & 329,468 & 323,907 & 341,718 \\
\hline & Med & 209,955 & 204,773 & 241,645 & 221,934 & 233,092 \\
\hline & StDev & 368,002 & 326,295 & 306,236 & 254,536 & 314,876 \\
\hline \multicolumn{7}{|l|}{ Outputs } \\
\hline \multirow[t]{3}{*}{ Gross Written Premium } & Mean & 557,640 & 556,942 & 573,752 & 583,226 & 587,640 \\
\hline & Med & 461,019 & 437,141 & 530,588 & 576,847 & 638,138 \\
\hline & StDev & 383,092 & 357,651 & 300,382 & 283,465 & 247,562 \\
\hline
\end{tabular}

Source: Author

Table 4. CCR model-efficiency scores.

\begin{tabular}{|c|c|c|c|c|c|c|}
\hline DMU & 2009 & 2010 & 2011 & 2012 & 2013 & Mean \\
\hline Albsig & 0.42849 & 0.50109 & 0.70874 & 0.75304 & 0.88089 & 0.65445 \\
\hline Viner & 0.68191 & 0.74668 & 1.00000 & 1.00000 & 1.00000 & 0.88572 \\
\hline Evroins & 0.51966 & 0.63767 & 0.74361 & 0.89800 & 0.81266 & 0.72232 \\
\hline Eurolink & 1.00000 & 0.97253 & 1.00000 & 1.00000 & 1.00000 & 0.99451 \\
\hline Insig & 0.33009 & 0.40532 & 0.55968 & 0.49945 & 0.55377 & 0.46966 \\
\hline Kjubi & 0.86513 & 0.46304 & 0.43388 & 0.48078 & 0.56247 & 0.56106 \\
\hline Kroacija & 0.63578 & 0.44792 & 0.66086 & 0.72089 & 1.00000 & 0.69309 \\
\hline Sava & 1.00000 & 1.00000 & 1.00000 & 1.00000 & 0.97779 & 0.99556 \\
\hline Triglav & 1.00000 & 1.00000 & 1.00000 & 0.98749 & 0.90514 & 0.97853 \\
\hline Unika & 0.55314 & 0.56539 & 0.66700 & 0.66242 & 0.74539 & 0.63867 \\
\hline Mean & 0.71403 & 0.67790 & 0.78464 & 0.79887 & 0.84387 & 0.76386 \\
\hline
\end{tabular}

Source: Author

Table 5. BCC model-efficiency scores.

\begin{tabular}{|c|c|c|c|c|c|c|}
\hline DMU & 2009 & 2010 & 2011 & 2012 & 2013 & Mean \\
\hline Albsig & 0.61734 & 0.62859 & 1 & 1 & 1 & 0.84919 \\
\hline Viner & 1 & 1 & 1 & 1 & 1 & 1 \\
\hline Evroins & 0.59625 & 0.71753 & 0.74388 & 1 & 0.83129 & 0.77779 \\
\hline Eurolink & 1 & 1 & 1 & 1 & 1 & 1 \\
\hline Insig & 0.67936 & 1 & 1 & 1 & 1 & 0.93587 \\
\hline Kjubi & 0.87513 & 0.60812 & 0.61899 & 0.55863 & 0.65218 & 0.66261 \\
\hline Kroacija & 1 & 1 & 1 & 1 & 1 & 1 \\
\hline Sava & 1 & 1 & 1 & 1 & 1 & 1 \\
\hline Triglav & 1 & 1 & 1 & 1 & 1 & 1 \\
\hline
\end{tabular}




\begin{tabular}{lllllll}
\hline DMU & $\mathbf{2 0 0 9}$ & $\mathbf{2 0 1 0}$ & $\mathbf{2 0 1 1}$ & $\mathbf{2 0 1 2}$ & $\mathbf{2 0 1 3}$ & Mean \\
\hline Unika & 0.60592 & 0.64398 & 0.6842 & 0.66401 & 0.84668 & 0.68896 \\
Mean & 0.84966 & 0.85434 & 0.90253 & 0.91112 & 0.92502 & 0.88854 \\
\hline
\end{tabular}

Source: Author

Table 6. Scale efficiency scores $(C C R / B C C)$ and returns to scale specification.

\begin{tabular}{|c|c|c|c|c|c|c|c|c|c|c|}
\hline DMU & 2009 & & 2010 & & 2011 & & 2012 & & 2013 & \\
\hline Albsig & 0.694 & IRS & 0.797 & IRS & 0.709 & IRS & 0.753 & IRS & 0.881 & IRS \\
\hline Viner & 0.682 & IRS & 0.747 & IRS & 1.000 & CRS & 1.000 & CRS & 1.000 & CRS \\
\hline Evroins & 0.872 & IRS & 0.889 & IRS & 1.000 & DRS & 0.898 & IRS & 0.978 & IRS \\
\hline Eurolink & 1.000 & CRS & 0.973 & IRS & 1.000 & CRS & 1.000 & CRS & 1.000 & CRS \\
\hline Insig & 0.486 & IRS & 0.405 & IRS & 0.560 & IRS & 0.499 & IRS & 0.554 & IRS \\
\hline Kjubi & 0.989 & & 0.761 & DRS & 0.701 & DRS & 0.861 & DRS & 0.862 & DRS \\
\hline Kroacija & 0.636 & IRS & 0.448 & IRS & 0.661 & IRS & 0.721 & IRS & 1.000 & CRS \\
\hline OsiguritelnaPolisa & 0.864 & IRS & 0.897 & IRS & 0.973 & IRS & 0.982 & DRS & 0.999 & DRS \\
\hline Sava & 1.000 & CRS & 1.000 & CRS & 1.000 & CRS & 1.000 & CRS & 0.978 & DRS \\
\hline Triglav & 1.000 & CRS & 1.000 & CRS & 1.000 & CRS & 0.987 & DRS & 0.905 & DRS \\
\hline Unika & 0.913 & IRS & 0.878 & IRS & 0.975 & IRS & 0.998 & DRS & 0.880 & DRS \\
\hline Mean & 0.830 & & 0.800 & & 0.871 & & 0.882 & & 0.912 & \\
\hline DMU's operating at CRS (\%) & $27 \%$ & & $18 \%$ & & $36 \%$ & & $27 \%$ & & $27 \%$ & \\
\hline DMU's operating at DRS (\%) & $9 \%$ & & $9 \%$ & & $18 \%$ & & $36 \%$ & & $45 \%$ & \\
\hline DMU's operating at IRS (\%) & $64 \%$ & & $73 \%$ & & $45 \%$ & & $36 \%$ & & $27 \%$ & \\
\hline
\end{tabular}

Source: Author

The scale efficiency of the Macedonian insurance sector follows the same trend as the technical efficiency i.e. permanent growth during the whole observed period with exception of the year 2010. From 2009 till 2011 the insurance companies in Republic of Macedonia are dominantly operating at increasing return to scale meaning that their small size was an efficiency problem. This situation changes from 2012, since when the largest portion of insurance companies are operating at decreasing return of scale i.e. most of the Macedonian insurance companies need downsizing in order of efficiency increase.

\section{Conclusion}

This paper endeavors to evaluate the extent of technical, pure technical and scale efficiency of the Macedonian insurance sector for the period 2009-2013. The efficiency has been measured using both $\mathrm{CCR}$ and $\mathrm{BCC}$ output-oriented DEA models. The results from the analysis indicate an increase of the average efficiency during the almost whole observed period. The scale efficiency follows the same trend.When estimating the BCC model, the number of efficient insurance companies and the average efficiency for the sector is higher than in the CCR case, implying that the main source of inefficiency is due to scale inefficiencies. The average technical efficiency score of Republic of Macedonia in 2013 of 0.84387 indicates relatively high efficiency of the insurance sector.

The results of the analysis show that three insurance companies (Eurolink, Sava and Triglav) are the most efficient on Macedonian insurance market, both technically and scale, during the whole observed period. Those companies show a great input productivity and highly successful managerial performance in organization of that inputs in the production process. During the almost whole observed period they are operating at constant return of scale i.e. the companies' size is optimal.

Viner is an insurance company that has experienced scale inefficiency in 2009 and 2010 due to operating at sub-optimum scale size. The problem has been exceeded in 2011, and since then Viner has the highest both technical and scale efficiency scores. Kroacija has been in the same situation as Viner, operating at increasing return to scale, but in 2013 its technical and pure technical efficiency scored the maximum score of 1 .

Albsig and Insig have the highest pure technical efficiency scores since 2010. The main source of their inefficiency is due to the scope of production. Since these companies are operating at sub-optimum scale size it is expected that their enlarging will lead to an efficiency increase.

The rest of the Macedonian insurance companies have both technical and scale efficiency problems. While the main source of scale inefficiency in the insurance sector of Republic of Macedonia is in the sub-optimum scale size, Kjubi is the only company that is operating at decreasing return of scale during the whole observed period. Downsizing of its operations should lead to an efficiency increase.

\section{References}

[1] Ayele, A. G. (2012): Factors Affecting Profitability of Insurance Companies in Ethiopia: Panel Evidence, Addis Ababa University, Addis Ababa, Ethiopia,available at: http://etd.aau.edu.et/dspace/bitstream/123456789/4326/1/Fact ors $\% 20$ Affecting $\% 20$ Profitability $\% 20$ of $\% 20$ Insurance $\% 20 \mathrm{Co}$ mpanies\%20in\%20Ethiopia.pdf, assessed on 12.05.2014. 
[2] Barros, C., P. and Obijiaki, E., L. (2007), Technical Efficiency of Nigerian Insurance Companies, Working Paper 018/2007/DE/UECE, School of economics and management, Technical university of Lisbon, available at: http://www.iseg.utl.pt/departamentos/economia/wp/wp018200 7deuece.pdf, assessed on 01.07.14.

[3] Borges, M. R., Nektarios, M. and Barros, C., P. (2008), Analyzing the Efficiency of the Greek Life Insurance Industry, European Research Studies, Volume XI, Issue (3) 2008.

[4] Diboky, F., and Ubl, E. (2007), Ownership and Efficiency in the German Life Insurance market: A DEA Bootstrap Approach, available http://www.aria.org/meetings/2007papers/VIB\%20-\%202\%20 -\%20Diboky.pdf, assessed on 08.07.14.

[5] Eling, M. and Huang, W., (2011), An Efficiency Comparison of the Non-life Insurance Industry in the BRIC Countries, Working Papers on Risk Management and Insurance, No. 94 November 2011, available at http://www.ivw.unisg.ch/ /media/internet/content/dateien/insti tuteundcenters/ivw/wps/wp94.pdf.

[6] Eling, M. and Luhnen, M., Frontier Efficiency Methologies to Measure Performace in the Insurance Industry: Overview and New Empirical Evidence, available at: http://www3.imperial.ac.uk/pls/portallive/docs/1/48187710.P DF, assessed on 01.07.14.

[7] Insurance Supervision Agency: Insurance Industry Reports Various editions, available at: http://www.aso.mk/index.php?option=com_sectionex\&view= category\&id=6\&Itemid=72\&lang=en.

[8] Jarraya, B. and Bouri, A. (2012), Efficiency concept and investigations in insurance industry: A survey, MPRA Paper No. 53544, Management Science Letters, Vol. 3, No. 1 (2013): pp. $39-54$.

[9] Kumar, S., Gulati, R., (2008), An Examination of Technical, Pure Technical, and Scale Efficiencies in Indian Public SectorBanks Using Data Envelopment Analysis, Eurasian Journal of Business and Economics 2008, 1 (2), 33-69.
[10] Leverty, J., T. and Grace, M., F. (2008), Issues in measuring the efficiency of property-liability insurers, available at: http://www3.imperial.ac.uk/pls/portallive/docs/1/48217697.P DF, assessed on 08.07.14.

[11] Sarkis, J., (2002), Preparing Your Data for DEA, Productivity Analysis in the Service Sector with Data Envelopment Analysis, 2nd Edition, available at: www.clarku.edu/ jsarkis/SarkisChapter.doc, assessed on 22.07.13

[12] Shahroudi, K., Teleghani, M., Mohammadi, G. (2012), Application of Two-Stage DEA Technique for Measuring of Private Insurance Companies in Iran, International Journal of Applied Operational Research, Vol. 1, No. 3, pp. 91-104, Winter 2012.

[13] Sihna, R. P.,Chatterjee, B., Are Indian Life Insurance Companies Cost Efficient?,available at: http://www.igidr.ac.in/money/mfc-11/Sinha_Rampratap.pdf assessed on 11.07.14.

[14] Stavarek, D., Repkova, I., (2012), Efficiency in the Czech Banking Industry: a Non-parametric Approach, Actauniversitatisagriculturaeetsilviculturaemendelianaebrunen sis, Volume LX, Number 2, 2012.

[15] Qui, S., and Chen, B. (2006), Efficiencies of Life Insurers in China - An Application of Data Envelopment Analysis, available at: http://www.ccfr.org.cn/cicf2006/cicf2006paper/200601300333 45.pdf,assessed on 08.07.14.

[16] Vinkova, Kristina (2005), Using DEA Models to Measure Efficiency, BIATEC, Volume XIII, 8/2005, National Bank of Slovakia.

\footnotetext{
${ }^{4}$ Efficient banks are those with efficiency score of 1 .

${ }^{5}$ Ibid.
} 